Journal of Sustainable Development of Transport and Logistics

journal home page: https://jsdtl.sciview.net

Tulu, G. S., Hadgu, M., \& Tarekegn, A.G. (2019). Bicycling in Addis Ababa, Ethiopia:

Opportunities and challenges. Journal of Sustainable Development of Transport and Logistics, 4(2), 50-59. doi:10.14254/jsdtl.2019.4-2.5.

\title{
Bicycling in Addis Ababa, Ethiopia: Opportunities and challenges
}

\author{
Getu Segni Tulu *(D), M. Hadgu **, A.G. Tarekegn *** \\ * Vital Strategies, Ethiopia office, \\ Addis Ababa, Ethiopia \\ getusegne@yahoo.com \\ ** School of Civil and Environmental Engineering, \\ Addis Ababa Institute of Technology, Addis Ababa University, \\ Addis Ababa, Ethiopia \\ me.wi1984@gmail.com \\ *** School of Civil and Environmental Engineering, \\ Addis Ababa Institute of Technology, Addis Ababa University, \\ Addis Ababa, Ethiopia \\ abrham.gebre@aait.edu.et
}

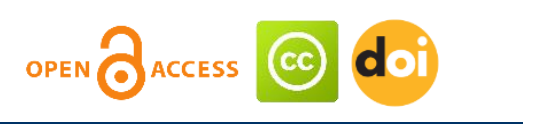

Article history:

Received: May 07, 2019

1st Revision: August 19, 2019

Accepted: November 20, 2019

DOI:

10.14254/jsdtl.2019.4-2.5
Abstract: Addis Ababa is urbanizing at an increasing rate. Mobility problems and related negative impacts of motorized traffic and associated road safety issues remained to be a big challenge to the city. Improved cycling environment can play a greater role in solving those issues through reducing the exposure to risk of crashes and leading to a sustainable urban transportation. Among others, the benefits of increased level of bicycling are; health and physical fitness, clean environment, safe and cheap mode of transportation, particularly for a developing city like Addis Ababa. Regardless of the significant benefits of bicycling, the use of the bicycle as a mode of transportation in Addis Ababa is currently negligible and understudied. Furthermore, the cycling environment of the city faces many challenges. Some of the challenges are; lack of bicycle infrastructures, poorly maintained infrastructure, lack of bicycle policy and strategy. The supply of bicycle with reasonable price and lack of awareness of the benefits of using cycling as a mode of transportation are also another issue in the city. This paper is prepared to provide a review of the literature on the opportunities and challenges of bicycling in Addis Ababa. It focuses on evidence of (i) the opportunities of bicycling along with its challenges, and (ii) the current status of the cycling environment in the city. The main objective of this paper is to collect evidences that outline the potentials and problems the city faces to achieve a better cycling environment. It is expected to provide important information that can be used by transport planners, policy makers and researchers of the city improve the

Corresponding author: Getu Segni Tulu

E-mail: getusegne@yahoo.com

This open access article is distributed under a Creative Commons Attribution (CC-BY) 4.0 license. 
cycling environment. Going forward, the city has the intention to prioritize Non-Motorized Transport, including cycling in the city.

Keywords: Addis Ababa, bicycle, challenges, mobility, nonmotorized transport, opportunities

\section{Introduction}

Addis Ababa, the capital city of Ethiopia, has the estimated population of 7.8236 million in 2019 (Population of 2019, 2019) and seats many international diplomats. It is a third diplomatic city next to New York and Geneva. Nowadays, the city is characterized by a rapid population growth, which is supported by expansion of economic activities. Many expatriate investors have turned their eyes on the city.

The Rapid development (both horizontal and vertical) of the city (Kasa et al., 2011) and the two digit growth of the country have resulted in a rapid expansion of the urban area; which in turn has generated many transports, housing, and infrastructure deficits, as well as alarming environmental degradation (Addis Ababa City Administration, 2018). These stem a serious problem in the transportation system of the city in terms of efficiency and safety perspectives.

On the other hand, politicians, planners and professional engineers have given emphasis to build roads for cars, which are used by a few citizens. Thus, motorized transportation oriented attitude dominated city transport planning even though the city has developed a transport strategies, particularly for non motorized transportation. However, motorized transportation has brought serious issues related to air and noise pollution in the city (Etyemezian et al., 2005). In addition, road traffic crashes are also considered as emerging problem as 478 people dead in 2018 out of which about 80 percent were pedestrians (Bloomberg Initiative for Global Road Safety, 2018).

Many tax payers are not using much motorized transportation in their day to day life. For instance, studies show that walking is a dominant means of transportation in the city, which accounts for 54 percent of the transport modal share (Tulu, 2013; Bogale, 2012; Addis Ababa City Administration, 2018; Teklu, 2015; World bank, 2016) and the public transport, which include bus, blue minibus taxis, and Light Rail Transit (LRT) covers 31 percent of city transportation, which are not easily available due to the long waiting time and overloading of passengers. Private car users cover the remaining $15 \%$. Out of the total vehicle population in the country, about 70 percent are registered in Addis Ababa (Akloweg et al., 2011), which has a negatively impact on the environment and safety of the citizens. Again, most of registered vehicles are long-lived or entered the country as a second hand, which poses series problem of pollution due to emission and wastage of resources through poor maintenance and heavy spare part requirements.

In contrast, cycling has an insignificant share in the modal transport of the city because of many reasons. As mentioned previously, the focus of the city officials was to construct a roadway for motorized traffic instead of non-motorized. Although the city government has made some effort to improve the Non-Motorized Transport (NMT) environment, the attention given to bicycling and bicycle infrastructures are almost negligence (Eshetu, 2015; Addis Ababa City Administration, 2018; Teklu, 2015), which include lack of bicycle infrastructure, dangerous intersection or crossing bicycle riders and poor maintenance as most transport investment in the past has gone for building of motorized traffic infrastructure (Ministry of Transport, 2011). On the other end, the other one is the cost of owning a bicycle is considerable and expensive. As a result, the citizens are not able to own it. The country as well as the city didn't have a to encourage bike riding in the city until recent year, which encourage the people toward bicycle ridings. The aim of this paper is, therefore, to provide a review of the literature on the opportunities and challenges of bicycling in Addis Ababa and to suggest appropriate remedies on how to boost bike riding in the city to the city planners and administrators. It focuses on evidence of (i) the benefits of bicycling along with its challenges, and (ii) the current status of the cycling environment in the city. Again, the main objective of this paper is to collect evidences that outline the potentials and problems the city faces to achieve a better cycling environment. 
Furthermore, it will assess the bicycling environment of the city from different dimensions. Hence, the outcome will provide a comprehensive overview of the challenges faced as well as the opportunities available for cycling in Addis Ababa. It can also contribute a great scientific knowledge to the very little available literature of cycling in the city of Addis Ababa.

\section{Methods}

In this report a synthesis of available literatures was conducted in order to explore the opportunities and challenges of bicycling in Addis Ababa. First, by focusing on the importance/benefits of cycling and cycling infrastructures, thorough review of a number of scientific researches, strategic and policy reports, books, articles, and blog posts to prove that bicycling is a viable and sustainable mode of urban transport. Second, the challenges and barriers to bicycling were explored from literatures around the world. Third, the overall image of transportation in Addis Ababa was reviewed from different dimensions trying to get a sense of the role that bicycling can play in the city's urban mobility challenges. Forth, as the city seeks to prioritize Non-Motorized Transport (NMT), the recently developed Addis Ababa's NMT strategies along with its implementation plan were reviewed. Finally, a small questionnaire survey has been conducted to explore their awareness on bicycle and its associated challenges. Descriptive statistics were deployed to analyze the data.

\section{Results}

\section{Synthesis of the Opportunities and initiatives of Bicycling in Addis Ababa}

Bicycling as mode of transport has not been given attention for a long time. Very recently, the city has formulated non-motorized transport strategy and action plan which promotes the development of bicycle infrastructure, and its use. The city has many opportunities and emerging challenges of bicycle in Addis Ababa and some of them are outlined here below.

\section{Non-Motorized Transport Strategy}

The NMT strategy has prepared under the fund provided by UN Habitat and UN environment. The preparation of the strategy has been carried out with the collaboration of the Institute for Transportation \& Development Policy (ITDP) with city institutes (Transport Programs Management office and City's Road and Transport Bureau). The strategy has given a top priority of walking and cycling in the Addis Ababa road network (Addis Ababa City Administration, 2018). Similarly, the new city's master plan has recognized the importance of non motorized transport and allocated 50 percent of the right of way of the road on average (Addis Ababa City Plan commission, 2017). Thus, all these strategic documents to assist the city and pave the path for the promoting active transportation (cycling and walking) in the city.

\section{Identify current and future bicycle network}

Following the strategic plan of non-motorized transport, Bloomberg initiative for Global Road Safety and its partners are working on the identification of bicycle network. In particular, the National Associate City Transport officials (NACTO) have taken the assignment and identified the potential place in the road network (Addis Ababa City Administration, 2018). This concept design is already ready for the capital investment, which may require finding funding for the construction of bicycle infrastructure from the local city budget as well as from donors and multinational lenders. The NMT strategy has forwarded a direction to construct about $200 \mathrm{~km}$ bicycle lanes /truck within the coming 10 years (Addis Ababa City Administration, 2018). The master plan and NMT strategies align each other on cycling facilities, which is big policy potential for the expanding bicycling in the city.

\section{Bicycle Design Guide}

The design guide for bicycle infrastructure is not in place in the city. Some attempts have been made towards the construction, bicycle lanes in three selected areas of the city based on the guide available internationally. Even though the international partners (National Associate City Transport officials and World resource institute (NACTO)) have reviewed the design, implementation/construction has not been carried out fully according to the design. For instance, the intersections are not laid out properly. Drainage problems are big issues and Water inundate on the bicycle lane in rainy season. Moreover, the pavement structure at the intersection are not designed and constructed based the standard axle load through, which the pavement are exhibited some 
distress due to the navigation of the heavy trucks. Similarly, pedestrian sidewalk is poorly constructed and maintained. As a result, citizens prefer to walk on bicycle track, i.e. comfortable, convenient and interesting for them.

The importance of the design guide for bicycle infrastructure is well recognized by the city as well as by international partners, which are working on road safety of the city under the Bloomberg initiative for Global Road Safety(e.g. The World Bank, NACTO and World resource institute). The World Bank under Transport System Improvement Program has already allocated funding for the consultancy service of the preparation of the road transport design guide (World Bank, 2019), which give priority for the bicycling, and public transport guide. This will be expected to substitute current vehicle oriented design manual that might provide a great opportunity to develop a bicycle network in the city.

\section{Economic benefits for local business}

Most urban dwellers use the walking mode of transportation, which may need longer travel time and unsafe walking on the Addis Ababa road (Tulu, 2013a, 2013b) due to the road safety exposure to the risk of crashes. In addition, the majority of people may not afford the cost of public transport (Tulu, 2013b) and /or severe shortage of public transport in the city (Fanta, 2014) and as a result, the majority of the citizens prefer to walk in Addis Ababa. On the other hand, cycling has big economic benefit as compared to walking when they put the time saved and travel costs. Evidences from various countries reveal that bicycle as a mode of transportation has also wider economic benefits (Rajé \& Saffrey, 2016; Cornish, 2015). Retail business along the bicycle facilities and its influence areas has made more encouraging employment effects, and public spending efficiencies. Similarly, a study done in South Africa confirmed that bicycle riders save up to 45 percent of their monthly household income if they use bicycle frequently for all purpose trips as compared to public and mass transport (Bechstein, 2010).

\section{Developing Livable City}

The livable city is the new concept of least developed countries, which needs to improve their streets and neighborhoods through which walking, bicycling and mass transit. The opportunities that Addis Ababa is that many of the road users commute using walking mode (World Bank). The city also has potential for use of bicycles if the infrastructure, reasonable quality bicycles and their spare parts will be available at reasonable prices. Another is that the city should make cycling safer, comfortable, and interesting. As a result, many citizens could be attracted not only for their primary trips, but also for secondary trips and recreational activities.

The real time report of air pollution measured by the United States Embassy in Addis Ababa on selected areas of Addis Ababa revealed that the $\mathrm{PM}_{2.5}$ is as unhealthy for sensitive citizens of air quality index on May 14, 2019 (Addis Ababa US Embassy, 2019). This shows that the air pollution from road transport are getting worsen which may need to look for green transport like bicycling. Providing quality bicycle networks promote for creation of more accessible neighborhoods. In areas with low car ownership,bicycling provide cheap alternative access to employment, health care and services (HayenPerschon, 2001). In another study, focusing on producing and livable African cities, Langen \& Tembele (2000) started providing quality bicycle lanes also increases social cohesion and benefits to the well being of the whole community. People who travel by bicycle are 'happier' than users of other transport modes (Morris \& Guerra, 2015). In general bicycling provides a more intimate connection and social cohesion between people and their surroundings than a car (Grava, 2003). Thus, the city has a great potential to use bicycling if the city provides safe, comfortable, and interesting cycling facilities. In turn, the air quality, local business, establishing liable street and neighborhood will be improved and have ultimate effects of the life of citizens.

\section{Improve road Safety}

The use of non motorized transport can be an effective means for reducing exposure risk of crashes. In particular, the safety benefits of bicycling (Mobile2020 Project Consortium, 2013) have the reduction of the current road fatalities in the city. For example, like Seweden's zero vision road safety approach, and sustainable safety strategy of the Netherland, British has followed the danger reduction strategies, which focused by encouraging the city's non motorized transport. By doing this, the exposure to risk of crashes can substantially be reduced (Tight et al., 1998). The exposure to risk of crashes is directly related to the number of vehicles operated in the country even though their relationships are non linear (Elvik, 2014). 


\section{Car free days}

The city has committed to promote NMT and public transport through car free day. The program has been carried out on every first Sunday of the month, which was launched first time in December, 2018. Motorized traffic is banned in selected residential areas of major suburb from using the car for a half day to promote cycling and a healthy lifestyle. Citizens exercise bicycle riding, keyboard, walking, jogging and mass sport and running activities (TPMO, 2018). The event has brought a big impact on the exercising riding bicycle. Some examples bicycle riders and skyboard users are given Figure 1.

\section{Figure 1: Bicycle and skyboard riders on Car free days}

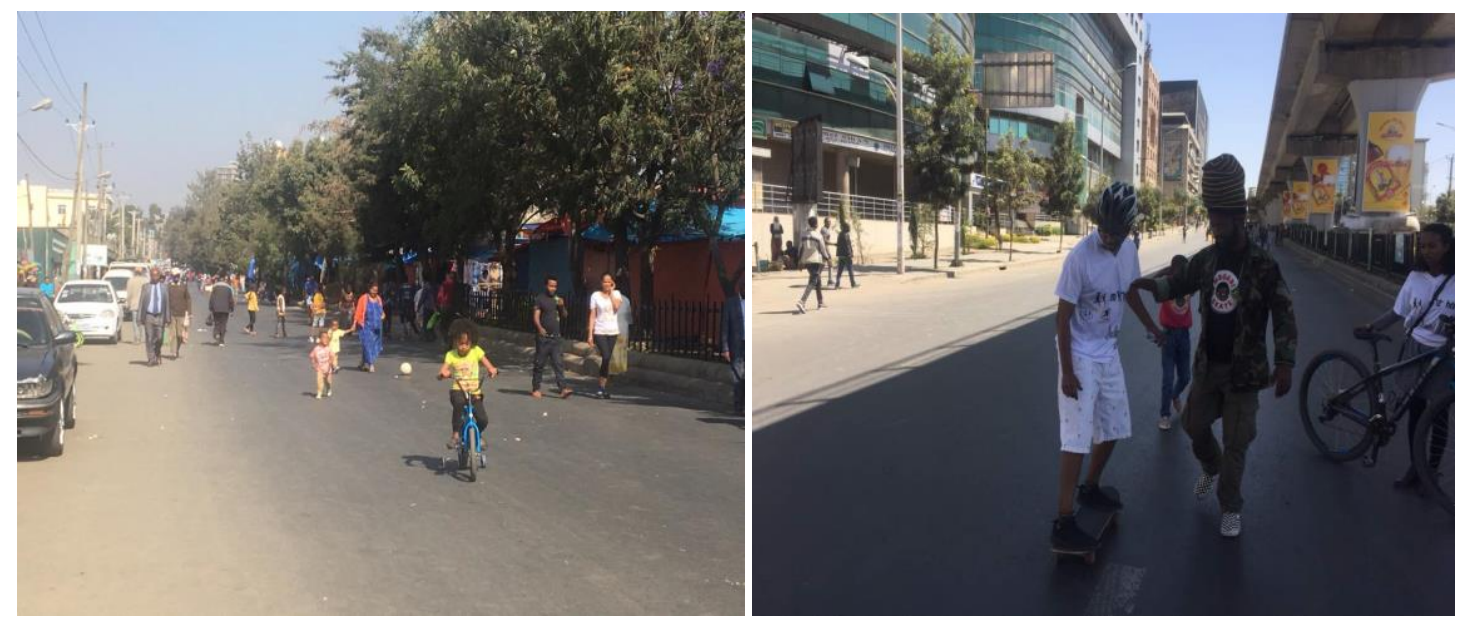

Source: Photo: From Traffic Management Agency

Currently, the ministry of health of Ethiopia has deployed around 5,000 bicycles for each session, which are used by public on car free day celebration. Citizens who haven't the skill of bicycle riding have the opportunities to scale up their experience. Small survey has been carried out around 385 respondents as part this study and findings revealed that most of citizens were not able to ride bicycle (see Figure 2). The opportunities car free days and the availability of bicycles encourage the use of bicycle riding even though most citizens don't have the economic capacity to own bicycle.

\section{Institutional capacity}

The city is already organized, responsible institution (the city Road Traffic Management Agency) for this work since 2017. Appropriate unit has also put in place in the Agency, which make follow up the work related to the development of NMT. Currently, the agency has no budget deficit and can collaborate with the city Road Authority to incorporate the bicycle network in the network.

\section{Synthesis of the Challenges of Bicycling in Addis Ababa}

Challenges in implementing sustainable bicycling and infrastructure in Addis Ababa have been observed. Some of them are discussed below.

\section{Poor land use planning}

Poor land use planning is critical issues for the development of bicycle network. Theoretically, the city master plan has shown to develop compact and connected city (Addis Ababa Plan Commission, 2017); however, unplanned horizontal expansion of the city is a problem in the provision of infrastructure. Houses and building have been constructed, without accounting for future transportation infrastructure demand. This may continue a challenge on the current and future bicycle network development of the city.

\section{Bicycle infrastructure}

Until very recently, the dedicated bicycle tracks were not available in the city. However, few citizens bike in the city by sharing with motorized traffic on the roadway. On the other hand, poor road safety also discourages people from cycling which could be solved with provision and proper design of cycling facilities (Teklu, 2015). Although lack of adequate bicycle infrastructure is a proven barrier to cycling (Parkinet., 2007), it is argued that the installation of cycling infrastructure alone is not sufficient to attract new cyclists (Handy \& Xing, 2011). Recent attempts in formulating nonmotorized transport strategy and identifying cycling network at the road network level of Addis Ababa encourage bicycle riders to make safe riding and comfortable, which may attract many citizens. 


\section{Theft of bicycles}

Bicycle theft is a serious issue in Addis Ababa as vital registration does not practice in the country and as a result, it is difficult to trace a person who takes away the rented bicycles. For instance, the city government organized small enterprises for those jobless citizens; however, they faced big problems of theft of their bicycles. Similarly, Bicycle theft is a common problem internationally; ordinarily it refers to the theft of the entire bicycle, but can also include the theft of component parts and accessories (Van Lierop, 2015).

On the other hand, GiZ of TUMI award has provided USD 200 thousand for the city administration for the establishment of bike sharing scheme for the last mile connectivity of the existing LRT and Rapid Bus Transit (ITDP \& Tumi Urban Global Mobility Challenge, 2019). Nearly 500 bicycles at more than 60 bike docks are planned to place them to transform the transportation of Addis Ababa. However, the theft could be challenging and may not be functioning as intended. Currently, various expatriate partners who are working with the city have been under discussion and their intention is to give emphasis on the provision of bicycle lanes by reclaiming space from motorized transport in the inner city.

\section{Owning Cost and Accessibility}

One of the most important constraints to cycling is found to be the lack of affordability of a bicycle (Mengesha, et al., 2002). According to Berger, et al. (2018), the upfront cost of purchasing a bicycle is the main barrier to cycling. From their survey, the barrier of bike expense (20 percent) and lack of access to bike (23.3 percent) were the most heavily selected. Likewise, the upfront cost of not only purchasing, but also maintains a bicycle is a major barrier in Ethiopia as the level of poverty the country has. Also, the landscape of Addis is hilly is not that convenient for riders to use the bike to their workplace and back.

\section{Survey results}

This study has circulated small questionnaire survey of 291 participates whose ages are over 15 years to identify the critical factors related to experience, and awareness of the benefit bicycling, and those questionnaires which have glory results are discussed.

\section{Experience use of bicycle}

Assessment has been done to identify their experience on the use of the bicycle for the last six months. All participants returned the questionnaire and the responses were shown on the pie chart. Nearly 76 percent of participants have no bicycle use for any reason in the last six months. This shows that bicycling in Addis Ababa has been means already a somewhat unusual transport option. Most citizens have not taken as a of transport for their primary and secondary mode of transport. This could justify by a number of factors. First, the citizen may not aware of the benefit of bicycling. The cost of owning bicycling is considerable for the citizens. The non existence of bicycle infrastructure may feel bicycle rides unsafe to share the roadway space with motorized transport.

Figure 2: Bicycle Use for any Reason in the Last Six Months $(n=291)$

\section{Bicycle use for any Reason in the Last Six Month}

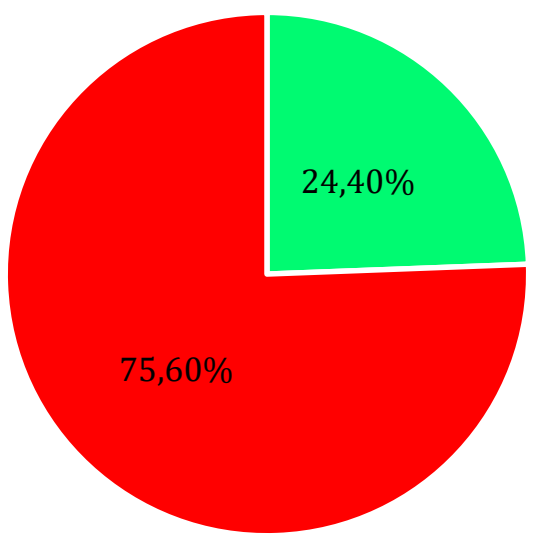


The analysis also extended to gage the awareness level of the citizens about the existence of bicycle infrastructure and most participants were not aware of the facility as last mile connectivity of LRT (see Table 1).

Table 1: Awareness on the existence of the three bicycle tracks in the Addis Ababa ( $\mathbf{n}=\mathbf{2 9 1})$
\begin{tabular}{|l|c|c|c|c|}
\hline \multicolumn{2}{|c|}{ Description } & No & \multicolumn{2}{c|}{ Yes } \\
\cline { 2 - 5 } & Count & Count & \% \\
\hline $\begin{array}{l}\text { Awareness on the Existence of the Three Bicycle Tracks } \\
\text { in the Addis Ababa }\end{array}$ & 248 & $85.22 \%$ & 43 & $14.76 \%$ \\
\hline
\end{tabular}

\section{User satisfaction of bicycle facilities}

Bicycling and bicycle facilities satisfaction were surveyed among those cyclists, and non-cyclists. The analysis focuses on the future existence of bicycle environment, design standard, better bicycling facilities add value to any community and various benefits of bicycling. Accordingly, most non cyclist participants respond positive responses, as shown in Figure 3.

\section{Figure 3: Bicycling and bicycle facilities satisfaction: Use and value (cyclists vs. non-cyclists)}

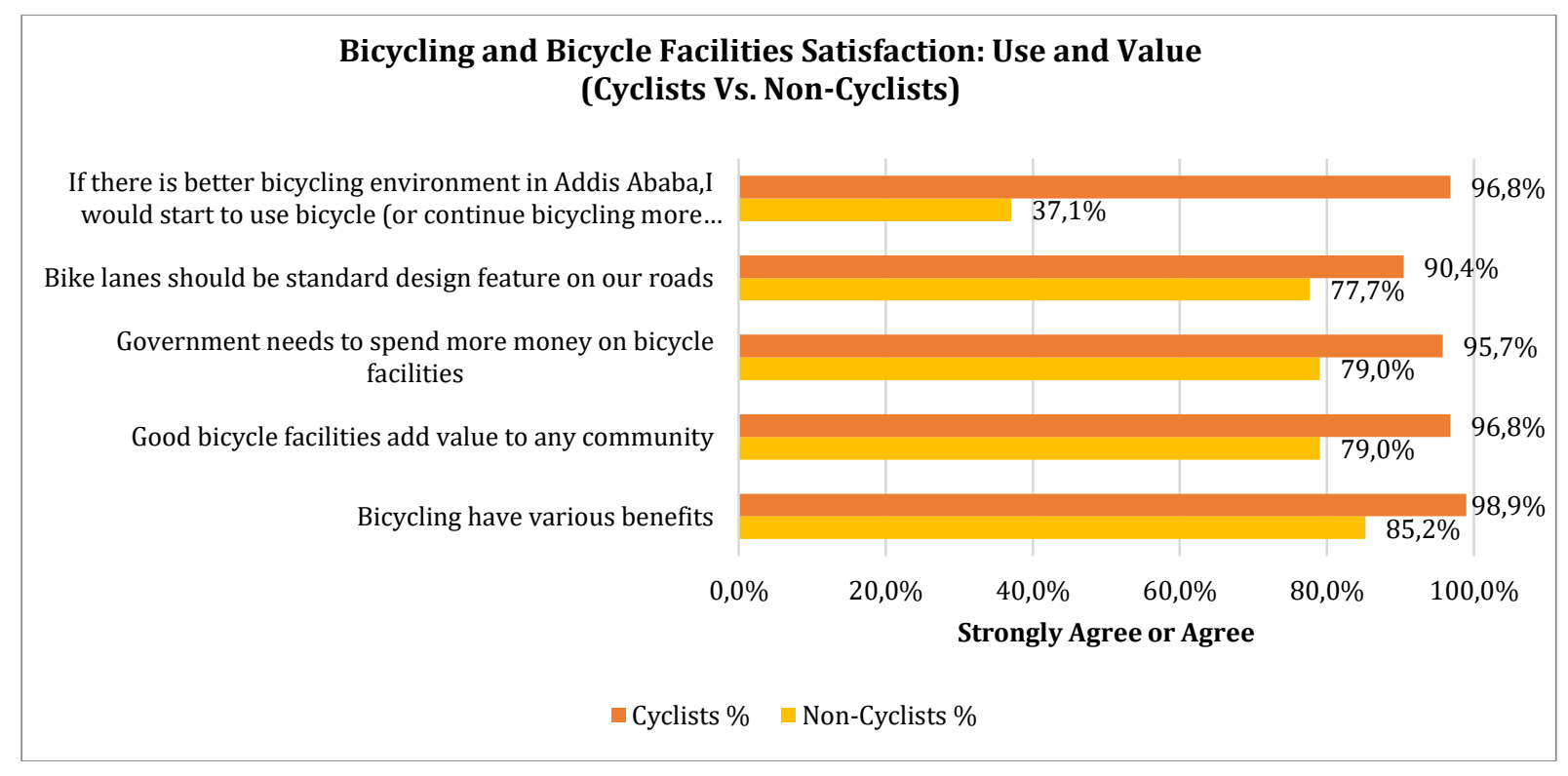

\section{Discussion}

Regardless of the many significant benefits of bicycling, bicycle use as a transportation mode is currently negligible in Addis Ababa. To date, there is no official statistical data for the level of cycling in the city. On one hand, many opportunities the city has to develop bicycle transportation option as mentioned previously. Most of the people in the city uses walking and public transport as a transportation mode. In a situation like this, with a well-planned and attractive cycling environment, it is easier to shift the modal share of public transport and walking than private car use, and in fact increase the level of cycling to a significant degree. The average trip length of the city (which is less than $5 \mathrm{~km}$ ) can also contribute in choosing to use the bicycle - a transport mode more convenient for short trip length. The city's ambitious plan to expand and reform the public transport gives a great opportunity to ensure improvements made to the cycling environment parallel to that of public transport. It can be easy and convenient to combine the use of both modes.

On the other hand, one of the major challenges to the cycling environment is the lack of bicycle infrastructures in the city. Cycle tracks exist only in three different locations, which were constructed as a pilot project in 2015, and are poorly designed and maintained. The pilot project included a bicycle rental program which also failed. These cycle tracks along with the signs, bicycle racks, benches and bicycle rental program which were all part of the pilot project should be investigated in detail. Lessons should also be taken from the pilot project for the future installation of bicycle infrastructures and bike sharing system. 
Moreover, most planning and execution of transportation projects has neither integrated nor transcended the economic, safety, reliability and environmental accounts of the transport infrastructure service provision, which includes NMT, especially cycling facilities. This finally turns to deliver outcomes, which are less aligned to the expectation of the citizens. Most time, things are fine at the planning stage as expatriates from affluent counties provide support and give their experience in formulating the plan and design of infrastructure related projects. This is mainly because the decision has been made by various infrastructure providers and transport operators separately, which in turn implies that responsibility and accountability for public money are not in place in the city as well as in the county level.

For instance, bicycle lanes constructed two or three years back in three sites of the city, which is a good demonstration of integration among infrastructure providers and operators. Another one is the quality of bicycles the city bought and distributed by organizing jobless citizens to work as a means of generating income by leasing the bicycle for short trips. Informal discussion has been made by organized small bicycle firms and they brought many problems for discussion. The bicycles bought for those small firms have not been found the spare parts within the city, which make the sustainability bicycle problematic and the quality of the bicycles are questionable. Currently, almost no one operates bicycle on the three sites. They have stopped renting of bicycles due to the technical bicycle and infrastructural problems. On the other hand, the bicycle infrastructure has maintenance and drainage problems as mentioned previously. In addition, the intersections are not properly laid down for safe bicycle crossing and other road users.

\section{Conclusion}

Addis Ababa has been going through a car-oriented environment for years. Going forward, the city seeks to prioritize bicycling. The city plans to expand the bicycle track network. The infrastructures should be coherent, direct, comfortable, safe and attractive. The planed bike sharing system should take lessons from the experience of the pilot project. Ensuring the accessibility of the system throughout the city is very important.

\section{Appendix A. Supplementary material}

Supplementary data associated with this article can be found, in the online version, at https://jsdtl.sciview.net

\section{Funding}

The authors received no direct funding for this research.

\section{Citation information}

Tulu, G. S., Hadgu, M., \& Tarekegn, A.G. (2019). Bicycling in Addis Ababa, Ethiopia: Opportunities and challenges. Journal of Sustainable Development of Transport and Logistics, 4(2), 50-59. doi:10.14254/jsdtl.2019.4-2.5.

\section{References}

Addis Ababa US Embassy. (2019, May 14). Addis Ababa US Embassy Air Pollution: Real-time Air Quality Index (AQI). https://aqicn.org/city/ethiopia/addis-ababa/us-embassy/. Accessed May 14, 2019.

Addis Ababa City Administration. (2019). Addis Ababa Non-Motorized Transport Strategy 2019-2018. Addis Ababa.

Addis Ababa Plan Commission. (2017). Master plan, Addis Ababa, Ethiopia.

Akloweg, Y., Hayshi, Y., \& Kato, H. (2011). The effect of used cars on African road traffic accidents: A case study of Addis Ababa, Ethiopia. International Journal of Urban Sciences, 15(1), 61-69. 
Bechstein, E. (2010). Cycling as a supplementary mode to public transport: a case study of low income commuters in South Africa. SATC 2010. Proceedings of the 29th Southern African Transport Conference (SATC 2010) 16 - 19 August 2010 Proceedings. Pretoria, South Africa.

Bloomberg Initiative for Global Road Safety. (2018). Addis Ababa Road Safety Annual Report 20172018. Addis Ababa City Administration. Addis Ababa.

Bogale, Y. A. (2012). Evaluating transport network structure: Case study in Addis Ababa, Ethiopia. University of Twente Faculty of Geo-Information and Earth Observation (ITC).

Cornish, L. (2015). Bike Shops for Everyone: Strategies for making bike retail more welcome to women. League of American Bicyclists in partnership. USA.

Grava, S. (2003). Urban Transportation Systems: Choices for Communities. New York: McGraw-Hill.

Elvik, R. (2014). Bidrag til en generell teori om forholdet mellom. Transportation Research Record, 2103, 25-31.

Eshetu, G. (2015). Bikeway Compatibility and Implementation Study on Selected Routes of Addis Ababa (Doctoral dissertation, Addis Ababa University).

Etyemezian, V., Tesfaye, M., Yimer, A., Chow, J. C., Mesfin, D., Nega, T., ... \& Wondmagegn, M. (2005). Results from a pilot-scale air quality study in Addis Ababa, Ethiopia. Atmospheric environment, 39(40), 7849-7860.

Berger, B., Reback, M., \& Palmatier, S. M. (2018). Addressing the Barriers to Bicycling: A Bike Access Program in Lewiston and Auburn, ME.

Fenta, T. M. (2014). Demands for urban public transportation in Addis Ababa. Journal of Intelligent Transportation and Urban Planning, 2(3), 81-88.

Handy, S. L., Xing, Y., \& Buehler, T. J. (2010). Factors associated with bicycle ownership and use: a study of six small US cities. Transportation, 37(6), 967-985.

Hayen-Perschon (2001). Non-Motorised transport and its socio-economic impact on poor households in Africa, Cost-benefit analysis of bicycle ownership in rural Uganda.

Kasa, L., Zeleke, G., Alemu, D., Hagos, F., \& Heinimann, A. (2011). Impact of urbanization of Addis Abeba city on peri-urban environment and livelihoods. Sekota Dry Land Agricultural Research Centre of Amhara Regional Agricultural Research Institute: Addis Ababa, Ethiopia.

De Langen, M., \& Tembele, R. (2001). Productive and Liveable cities: Guidelines for pedestrian and bicycle traffic in African cities.

Mengesha, T. et al. (2002). Scoping Study Urban Mobility in Three Cities: Addis Ababa, Dar es Salaam and Nairobi, Maputo Mozambique: Sub-Saharan Africa Transport Policy Program (World Bank and the United Nations Economic for Africa (UNECA). Transport Research Laboratory.

Ministry of Transport. (2011). Transport Policy of Addis Ababa, Federal Democratic Republic of Ethiopia Addis Ababa.

Mobile 2020 Project Consortium. (2013). Mobile 2020 Cycling in livable cities. Baltic Environmental Forum Deutschland e.V. Osterstraße 58 D-20259 Hamburg Matthias Grätz www.bef-de.org.

Morris, E. A., \& Guerra, E. (2015). Mood and mode: does how we travel affect how we feel?. Transportation, 42(1), 25-43.

Nallet, C. (2018). The Challenge of Urban Mobility: The Case Study of Addis Ababa Light Rail, Ethiopia. Sub Sheara Africa Program.

Pojani, D., \& Stead, D. (2015). Sustainable urban transport in the developing world: beyond megacities. Sustainability, 7(6), 7784-7805. doi:10.3390/su7067784. 
Population of 2019, (2019, April 23). Population of 2019. Retrieved from https:// populationof2019.com / population-of-addis-ababa-2019.html. (Accessed May 07, 2019).

Rajé, F., \& Saffrey, A. (2016). The Value of Cycling: rapid evidence review of the economic benefit of cycling, Department of Transport, University of Brigham, London. https://assets.publishing.service.gov.uk/government/uploads/system/uploads/attachment_data /file/509587/value-of-cycling.pdf. (Accessed May 10, 2019).

TDP \& Tumi Urban Mobility Challenge. (2019). Transformative Urban Mobility Initiate: Global Urban Mobility Challenge 2019. http://conferencias.cepal.org/IIconferencia_ ciudades2018/ Miercoles\%2017\% 20octubre/Pdf/S4_5_Mark\%20Major.pdf Accessed 02, 2019.

Teklu, F. (2015). Cycling as an Alternative for Improving Mobility in Addis Ababa.

Tight, M., Page, M., Wolinski, A., \& Dixey, R. (1998). Casualty reduction or danger reduction: conflicting approaches or means to achieve the same ends?. Transport policy, 5(3), 185-192.

Tiwari, A. (2011). Urban Air Pollution Caused by Automobiles in Addis Ababa, Ethiopia and Its Health Consequences. IUP Journal of Environmental Sciences, 5(3), 49-58.

TPMO. (2019). Report on the Car Free Days, Addis Ababa (Amharic version).

Tulu, G. S., Washington, S. \& King, M. J. (2013a.) Characteristics of Police-reported Road Traffic Crashes in Ethiopia over a Six Year Period the Road Safety Research, Policing and Education Conference 2013 (RSRPE2013), 2013 Brisbane, Queensland-Australia. Brisbane.

Tulu, G. S., Washington, S., King, M. J., \& Haque, Md. Mazharul (2013b). Why are pedestrian crashes so different in developing countries? A review of relevant factors in relation to their impact in Ethiopia. In 36th Australasian Transport Research Forum (ATRF): Transport and the New World City, 2-4 October 2013, QUT Gardens Point, Brisbane, Australia.

World Bank. (2019). Public Disclosure: Ethiopia: Transport Systems Improvement Project (TRANSIP) (P151819).

http://documents.worldbank.org/curated/en/817211527299654912/pdf/Disclosable -Versionof-the-ISR-Ethiopia-Transport-Systems-Improvement-Project-TRANSIP-P151819-Sequence-No04.pdf.( Accessed May 01, 2019)

World Bank. (2016). Project appraisal document on a proposed credit in the amount of SDR 2013 million (US\$ 300 million equivalent) to the Federal Democratic Republic of Ethiopia for a transport systems improvement project, s.l.: s.n.

van Lierop, D., Grimsrud, M., \& El-Geneidy, A. 2015. Breaking into bicycle theft: Insights from Montreal, Canada. International Journal of Sustainable Transportation, 9(7), 490-501.

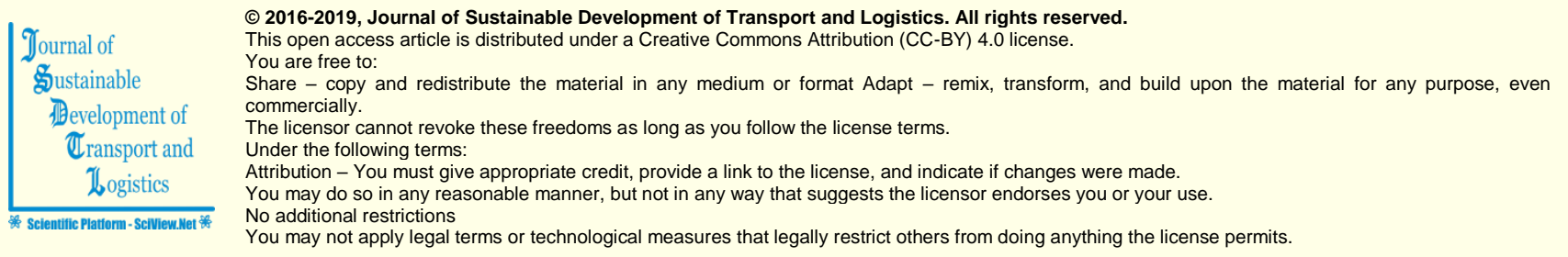

Journal of Sustainable Development of Transport and Logistics (ISSN: 2520-2979) is published by Scientific Publishing House "CSR", Poland, EU and Scientific Publishing House "SciView", Poland, EU

Publishing with JSDTL ensures:

riblishing with JSDTL ensures:

(n) visilich and discovesabilty via th

website

- Rapid publication

- Guaranteed legacy preservation of your article

- Discounts and waivers for authors in developing regions

Submit your manuscript to a JSDTL at https://jsdtl.sciview.net/ or submit.jsdtl@sciview.net 